\title{
THE IMPLEMENTATION OF GAMIFICATION IN MOBILE APPLICATION
}

\author{
Anamarija Šišić, Lidija Mandić (D), Ana Agić (D), Ante Poljičak (iD) \\ University of Zagreb Faculty of Graphic Arts, Zagreb, Croatia
}

\begin{abstract}
The aim of this research was to design mobile application that engages and motivates the end user to be physically active by promoting healthy habits. More and more services and mobile applications have begun to implement game elements. Competing application analysis found that the implementation of gamification should be unobtrusive recurring task cycle. The application was designated for young people and the results shown that implementation of gamification motivated them to be more active.
\end{abstract}

Key words: mobile application, gamification, user experience

\section{INTRODUCTION}

With the development of smartphone technology there is more competition on mobile application market. It is necessary to change design of application and adapt it to the needs of the end user. User experience (UX) is an interdisciplinary field of work, and it also includes the behaviors, attitudes and emotions that a user experiences when using a particular product, system, or service (Cao \& Gremillion, 2015). Since user experience involves multiple methods and processes that change over time and often come up with new forms of solving problems that are mostly related to the development of technology In that process user experience (Cao \& Ellis, 2015). One of the new methods for better UX in mobile application is implementation of gamification (Cao et al, 2015).

User-Centered Design (UCD) adapt user interface in a way that is consistent with the goals, tasks and needs of users. The main principles are: simplify the task structure to make actions intuitive, conceptual model need to be clear to the user, properly map the actions that leads to results and accept and take advantage of the limitations of the system. By applying these principles errors are reduced and users are more satisfy. This approach has disadvantage too due different view of how to solve the problem (Endsley \& Johnes, 2004).

It is important to define target users and understand the context in which the users interact with product. The elementary phases of each research should be: competition analysis, target audience analysis, design, evaluation and implementation of design. It is important to know target user group who will use product or service, outline their most important needs and expectations, the way how they will use it, and functionality. Best practice has shown that for a particular project three or four personas create. It is important to determine the main faction of mobile app. Personas should usually include name, gender, occupation, age, short bio etc. Most often after defining personas, user scenario is created. It helps to identify the main functionalities of mobile application, help to understand user habits and how they interact with the system (llama, 2018).

After this preliminary research, benchmarking is followed. When analyzing competition it is important to find out where the disadvantages are and how to solve them. After this, the wireframe is made, mostly low-fidelity prototype. It is important to emphasize that colors in this stage are not used except gray shades that indicate a different level of information architecture. Moreover, such a simple structure allows the designer to experiment in designing functionality and solves potential problems with the information structure in the future. Cycle iterations, testing, and feedback from users are a useful way of addressing possible shortcomings until the best possible version of the product is obtained. Usability testing refers to product assessment (mobile applications) by testing through representative users. During the test, the participants will try to fulfill certain tasks. The goal is to identify usability issues, collect qualitative and quantitative data, and identify participant satisfaction when using mobile apps. Games and UX design are often intertwined because they both share a unique feature that separates them from other media and this is interactivity. The term gamification developed in the year 2000 when designers began to consider how positive emotions and feelings can be triggered through sound, graphics, etc. to increase the user experience in interactions with the software. So gamification is not a synonym for gaming, it's just how designers can affect user behavior and motivate them as "gamers" to make the expected actions through elements of the game like challenges and prizes (Uxplanet, 2018). 
Gamification is based on human behavior, matched with natural learning and entertainment mechanisms. According to product design expert and famous author Nir Eyal, all user habits pass through four interconnected phases (Figure 1):

- $\quad$ Signs (or triggers) - visual data which encourage users to action

- Routines (or actions) - this is what the user actually plays in the game

- Awards - Include a move to the next level in the game and unlock achievements or items

- Investments - as players advance in the game, they become personally introduced into events and the final results of the game

\section{The hook canvas}

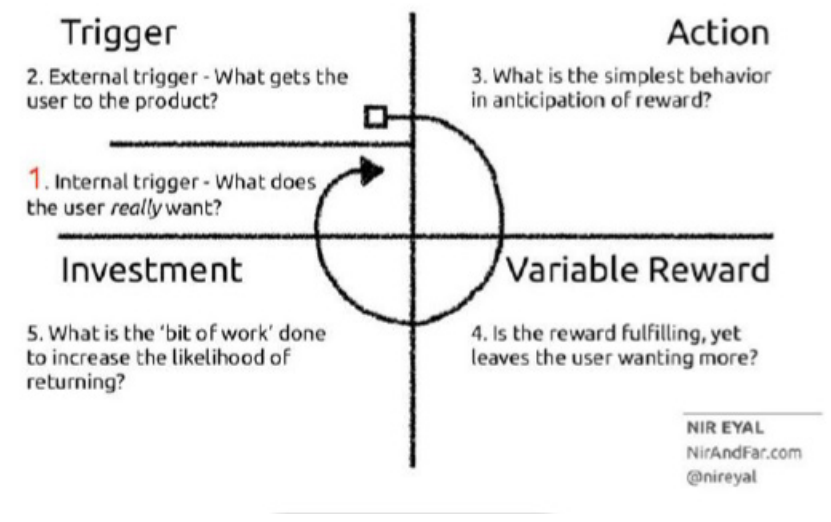

Figure 1: The process of integrating looping habits

\section{RESEARCH AND DESIGN}

The main goal of this research is the mobile application design for the Android operating system that engages and motivates the end user to be physically active by promoting healthy habits. From the beginning, part of the focus is on a system design that is easy to use and allows users to easily perform tasks, but more importantly, that the application, using game elements, is continually used. It was necessary to find what motivate users to use this app and what are the design strategies and gaming elements used in competing apps that motivate users to increase their physical activity. Three competitive applications were selected to study their functionality, motivation factors and possible usability problems: Nike+ Training Club, Zombies Run and Runkeeper.

From the above-mentioned analysis of competing applications it can be concluded that gaming implementation is a very complicated process, it must first be very subtle and unobtrusive. Also, it is important to realize the emotional connection of the user with the application because then the loop of habits begins to develop. What links all successful applications is a recurring task cycle - task execution feedback - a new task. As far as the user interface is concerned, it would be desirable that it is easy, without too much information, because it should be borne in mind that the user will use the application when performing the task in different environments.

Following UCDF it is important to have good personas and design the user interface appropriate for a particular group of users. The survey referred to user habits regarding motivation and physical activity. The survey were conducted through an online survey, and based on the results obtained personas were created. The survey was done with 56 users, and the Google forms tool was used to create a survey. The participants were mostly students (19-25). The survey participants received 10 questions with the offered answers. According to results mostly participants used Android smartphones. The questions were:

1. What is your occupation?

2. Which operating system you are using?

3. How much do you spend daily on physical activity on average?

4. Do activities like jogging, walking, swimming, exercising over time become dull?

5. Favorite physical activity? 
6. Do you play mobile games?

7. Do you use applications to increase productivity, track activity, weight and more?

8. Are you lacking motivation to keep your fitness goals?

9. If you had some reward for your ongoing activity, would you be more motivated then?

10. Would you use an app that rewards your ongoing activity and helps you move more?

Based on the results of the survey, three personas were created. Mostly participants answered that walking is their favorite activity. The application seeks to encourage users to enjoy their favorite activity, walking, in a fun way. The application "GOQUEST" has three functionalities that are related to the user's activity. The first functionality of the application is the so called "daily quest", which means a certain number of steps that the user passes on that day. The "daily search" functionality consists of a stylized map that the user can see on the home screen, this map indicates the way a user needs to pass that day. Additional maps, number of steps, miles, and time are provided with the map. When a user decides to overwrite a route that is the default on that day, he opens the map, the map shows the route that is generated from the user's location and ends near the user's initial location. The folder displays the points (3-5 points) that represent a certain character, or a badge that the user collects, these badges are actually a reward for a number of steps that a user makes on the road, for example, for 500 steps passed, the user wins one badge. The more steps you make or the more the badges accumulate over time the user is ranked higher in the ladder and for each level, the user is assigned one character and the name of that level, for example, "one level - a little monster".. The next functionality is to track user activity. When applying for a first registration, the user must enter some personal information such as weight and height information, then enter their goals, ie how many steps the daily minimum must (wants) to exceed. This functionality is divided into two parts, activities are primary while weight monitoring is secondary. The last feature is a table with the best results that changes each week and shows the best users, showing the number of steps past that week and the level that can be seen in the icon showing one of the main characters of the character (character). This functionality, though not primary, can motivate users to rank as much as possible on the ladder.

After the application's functionality is defined, the user interface sketch was made (Figure 2).

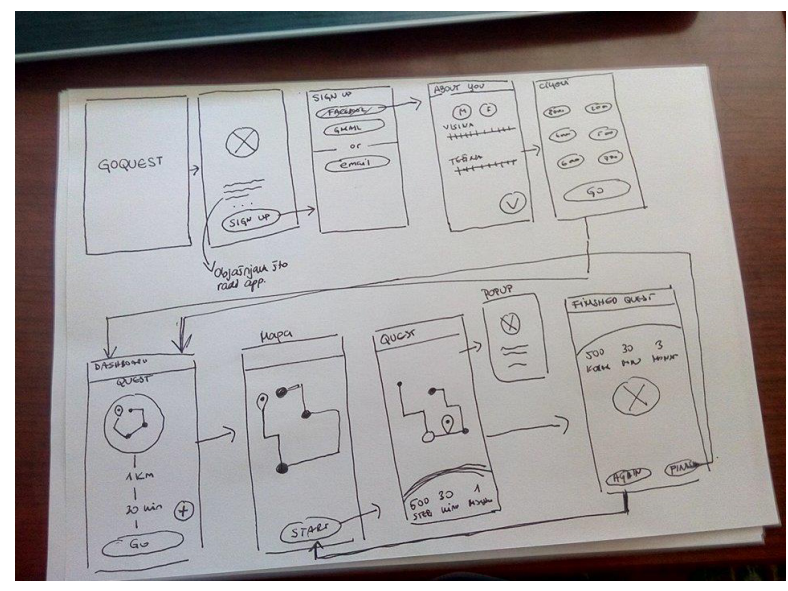

Figure 2: User interface layout

Prior to creating a prototype, the main app's apps have been defined. The main characters are small monsters that run through the application's functionality and their goal is to motivate users to perform activities. The main characters of the application are bright and saturated colors, so they have in some way defined the look of the rest of the interface, which is almost monochromatic and cleansed so that the user would not be overwhelmed with a lot of information and color. The application logo is made of the name of the application itself with a small eye detail inspired by the eyes of the main characters of this application. The eye is located inside the letter "Q", which looks like a magnifier with its appearance. This is to show the very essence of the app's own name, which is search, adventure, activity, and motivation. In Figure 3 are shown some screens of app. 

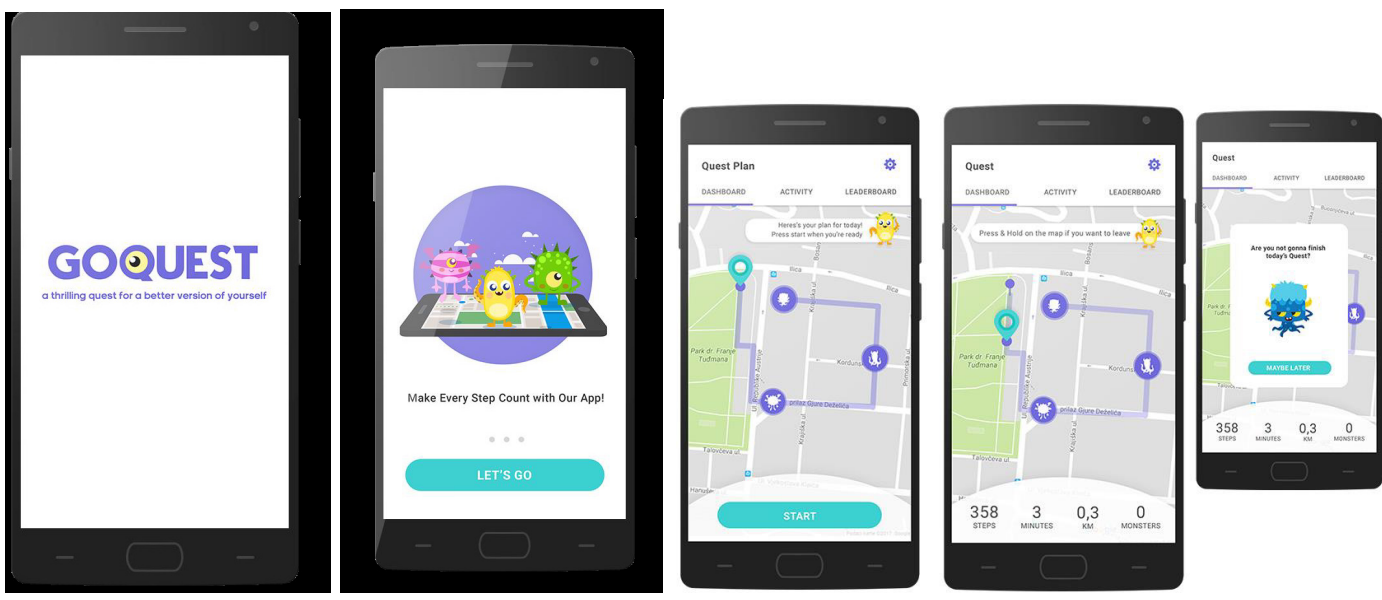

Figure 3: Splash screen, walk through, plan of activity, start, pop-up window

Participants are using a day prototype application via InVision prototype test site. Their task was to register through the application, set their own measures and go through the main functionality of the application. After the task was completed, participants answered questions about the application.

\section{CONCLUSIONS}

By analyzing the results of the survey conducted on the mobile application "GOQUEST", it comes to the conclusion that the functionality of the application is mostly clear to the respondents and easy to use. For example, showing the route on the map to most of the respondents (80\%) was very understandable. Also, the survey confirmed that the graphic design of the application leaves a positive impression on the respondents. From this it can be concluded that the visual style of this application does not require any further changes. The level or slate allocation system was either user-friendly or intuitive, so in that case it would be better to present the user with a level-allocation system, for example by creating a screen where the user can see what level is now and how many badges should be collected ) to the next level. In addition, questions about the motivational aspect of this app gave mostly positive answers, the vast majority of users would be able to show the activities and tables with the best results motivating them to move even further. Finally, most respondents gave a positive answer to the question of how fun their application is, so it can be concluded that the application of gamification in this app is successful. It can be concluded that the implementation of gamification in mobile applications definitely improves user experience.

\section{REFERENCES}

[1] Cao, J., Gremillion, B.: "UX Design Process, Best Practices", Uxpin, URL: https://www.uxpin.com/studio/ebooks/ux-design-process-documentation-best-practices/, (last request: 2018-05-10)

[2] Cao, J., Ellis, M.: "The elements of successful UX design", Uxpin, URL: https://www.uxpin.com/studio/ebooks/ux-design-successful-elements-for-products/, (last request: 2018-09-16)

[3] Cao, J., Nouvel, S., Ellis, M.: “UX Gamification redefined", Uxpin, URL: https://www.uxpin.com/studio/ebooks/ux-gamification-redefined/ (last request: 2018-07-07)

[4] Endsley, M.R., Johnes, D.,: “Designing for Situation Awareness, An Approach to User-Centered Design", $2^{\text {nd }}$ ed, (CRC Press, Boca Raton, 2011).

[5] Ilama, E.: "Creating Personas", Uxbooth, URL: http://www.uxbooth.com/articles/creatingpersonas/ (last request: 2018-08-08).

[6] Tubik Studio, Gamification in UX. Increasing User Engagement, Uxplanet, URL: https://uxplanet.org/gamification-in-ux-increasing-user-engagement-6437cbf702aa (last request: 2018-09-22). 


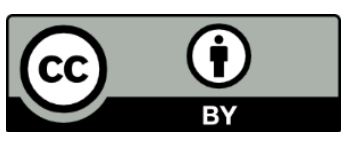

(C) 2018 Authors. Published by the University of Novi Sad, Faculty of Technical Sciences, Department of Graphic Engineering and Design. This article is an open access article distributed under the terms and conditions of the Creative Commons Attribution license 3.0 Serbia

(http://creativecommons.org/licenses/by/3.0/rs/). 